\title{
Mode Choice Analysis between Bus Rapid Transit and the Alternate Public Transit in Semarang City
}

\author{
Amelia Kusuma Indriastuti, Djoko Purwanto, and Kani Hari Basuki
}

\begin{abstract}
Since 2011, Government of Semarang City has planned the construction of a rail-based Mass Public Transportation System. This discourse is getting closer to realization in mid-2018, where the Semarang government sets Light Rail Transit (LRT) as the rail-based Mass Public Transportation System that will be implemented in 2019. Various opinions of the pros and cons rise due to the realization of this issue, in the midst of the slight number of public transport users in Semarang. This paper is a preliminary study that reviews the preferences of Semarang residents using Bus rapid Transit (BRT) to the LRT, with respondents coming from existing public transport users, such as Trans Semarang. Trans Semarang is the name of Bus Rapid Transit system in Semarang. The stated preference model between LRT with existing public transport vehicles used binomial logit analysis by considering the effect of changes in travel time and tariff. Based on the analysis of the preferences of Trans Semarang users on LRT, there are four conditions, namely: (1) When the LRT has the same travel time as Trans Semarang, the probability of LRT selection is $38.2 \%$. (2) When the LRT is 60 minutes faster than Trans Semarang, the probability of choosing the LRT increase to 43.5 percent. (3) When the LRT tariff is the same as Trans Semarang, the probability of the LRT election is $39 \%$. (4) When the LRT travel fare is Rp.10,000.00 higher than Trans Semarang, the probability of the LRT election decreases to $25.6 \%$.
\end{abstract}

Index Terms - Bus Rapid Transit, LRT, mode choice, public transit, Semarang City.

\section{INTRODUCTION}

$\mathrm{T}_{\mathrm{d}=\mathrm{h}}^{\mathrm{h}}$ he increase in economic activities and physical development of Semarang City increase new demand concentration, in addition to the existing ones. This changes the travel patterns. In recent years, travel on working day shows a large growth, especially during peak times. As a result, there is excessive traffic congestion on the main streets of Semarang City. To reduce the increasing number of

A.K. Indriastuti is with the Department of Civil Engineering, Diponegoro University, Jalan Prof. Soedharto, Tembalang, Semarang, Indonesia (e-mail: akindriastuti@gmail.com).

D. Purwanto is with the Department of Civil Engineering, Diponegoro University, Jalan Prof. Soedharto, Tembalang, Semarang, Indonesia (e-mail: djokpurwt@gmail.com).

K.H. Basuki is with the Department of Civil Engineering, Diponegoro University, Jalan Prof. Soedharto, Tembalang, Semarang, Indonesia (e-mail: basuki.kh@gmail.com) vehicles, the empowerment of mass public transport can be one solution. Hopefully, with the existence of a convenient and affordable mass public transport system, travelers with private vehicles will move using public transportation, so the number of vehicles on the road can be reduced.

With these considerations, in 2009 the Government of Semarang City launched a new road-based public transportation mode. This vehicle is a Bus Rapid Transit (BRT) type called Trans Semarang. Trans Semarang already has six corridors with non-exclusive lines (joining other vehicles). Due to the limited condition of existing road, geometric, the capacity of the road cannot be optimized for BRT lanes (using exclusive bus lane). As a result, the movement and performance of BRT is strongly influenced by traffic congestion. Travel time using BRT can be the same or even longer than the travel time using a private vehicle. In the end, more travelers choose private vehicles than BRT. Until 2017 there was no significant decrease in the number of private motorists.

To ensure the quality of public transport services, an increase in travel time and time reliability (timeliness of arrival and departure from the bus stop) is needed. One thing that can be done is to separate the movement of public transport with private vehicles (for example exclusive bus lanes, both on land and at elevated levels). For road-based transportation modes, this is quite helpful, but still there are points where public transport lines will meet private vehicles, so delays due to mixing with other traffic are still possible. Another alternative is to use rail-based Mass Public Transport System. The use of this rail-based mode of transportation can minimize conflicts with road-based private vehicles. Thus, the quality of public transport services can be guaranteed. In addition, rail-based modes have a much greater capacity than existing road-based public transport so that it can serve more passengers. Furthermore, this rail-based mode of transportation is expected to be able to divert private vehicle users to mass transportation modes.

Since 2011, Government of Semarang City has planned the construction of a rail-based Mass Public Transportation System. This discourse is getting closer to realization in mid 2018, where the government sets Light Rail Transit (LRT) as the rail-based Mass Public Transportation System that will be implemented in 2019. LRT is a light rail system that operates in the city center, connect one station to another station. The path required by the LRT is light and can be located around the existing road above the ground level (at grade), or has an 
elevated track. Thus, the procurement of land for LRT infrastructure relatively does not require a lot of land.

Various opinions of the pros and cons rise due to the realization of this issue, in the midst of the slightest number of public transport users in Semarang. This paper is a preliminary study that reviews the preferences of Semarang residents using the LRT, with respondents coming from existing public transport users, such as Trans Semarang.

\section{Preference AND Mode ChOICE}

\subsection{Preference}

In economic theory, preference is to sort choices based on available choices. This is a process that produces optimal choices. The preference of each individual is determined by taste factors, freedom of choice of price, income, and availability of products. There are two methods commonly used in preference analysis, namely Stated Preferences and Revealed Preferences.

The stated preference theory is based on estimated demand in an analysis of responses to hypothetical choices, this can include attributes and conditions in a wider scope than the real nature of the system. In the next stage the respondent chooses from the choices that have been determined, in some situation respondents are asked to make a ranking of the choices that are determined.

In the principle of transportation, Stated Preference is used as a means of approach in transportation system control which is made by holding a travel situation hypothesis, which refers to the approach by using the opinions of respondents in the face of various alternative choices. This theory offers a technique for providing information about demand and travel behavior well for a particular expenditure with a particular reason. This technique refers to an approach that uses statements about how respondents respond to different or changing situations. Furthermore, the Stated Preferences approach is more used in developing new modes of transportation that will be built.

Meanwhile, the Revealed Preference approach is used in various conditions related to environmental assessment and management assessment. The Revealed Preference approach uses information collected on the choices made by each individual to measure the statistical model of the needs scheme.

\subsection{Binomial Logistic Mode Choice Model}

There are three mode selection models that have been developed, namely the end-of-travel mode selection model, the mode of choice of travel exchange models and discrete selection models. These models should be solved using mathematical equation or statistical method, such as binomial logit.

Decision making on the binomial logit model is determined on a discrete alternative pair, where the alternative to be chosen is one that has the greatest utility, the utility in this case is seen as a random utility. The binomial logit model is divided into two, namely the binomial logit difference model and the binomial logit ratio model.

The binomial logit difference model is a modal selection model that uses a utility difference between the two types of modes that will be compared to determine the probability of choosing one of the modes offered.

1. Probability of mode a :

$$
P(a)=\frac{\exp U(a)-U(b)}{1+\exp U(a)-U(b)}
$$

2. Probability of mode $b$ :

$$
\mathrm{P}(\mathrm{b})=1-\mathrm{P}(\mathrm{a})=\frac{1}{1+\exp (\mathrm{U}(\mathrm{a})-\mathrm{U}(\mathrm{b}))}
$$

Where

$\mathrm{P}$ (a) = Probability of mode selection a;

$\mathrm{P}$ (b) = Probability of mode selection $\mathrm{b}$;

$\mathrm{U}(\mathrm{a})-\mathrm{U}(\mathrm{b})=$ binomial logit utility function of difference;

$\mathrm{U}(\mathrm{a}) \quad=$ Mode selection utility (a);

$\mathrm{U}(\mathrm{b}) \quad=$ Mode selection utility (b).

\section{METHOD}

To find out the public interest in LRT (which is still not available), interviews were conducted using a stated preference approach where respondents were given several questions regarding the situation comparing LRT with the existing modes they commonly used (in this case BRT), regarding travel time and travel costs, as follow: 


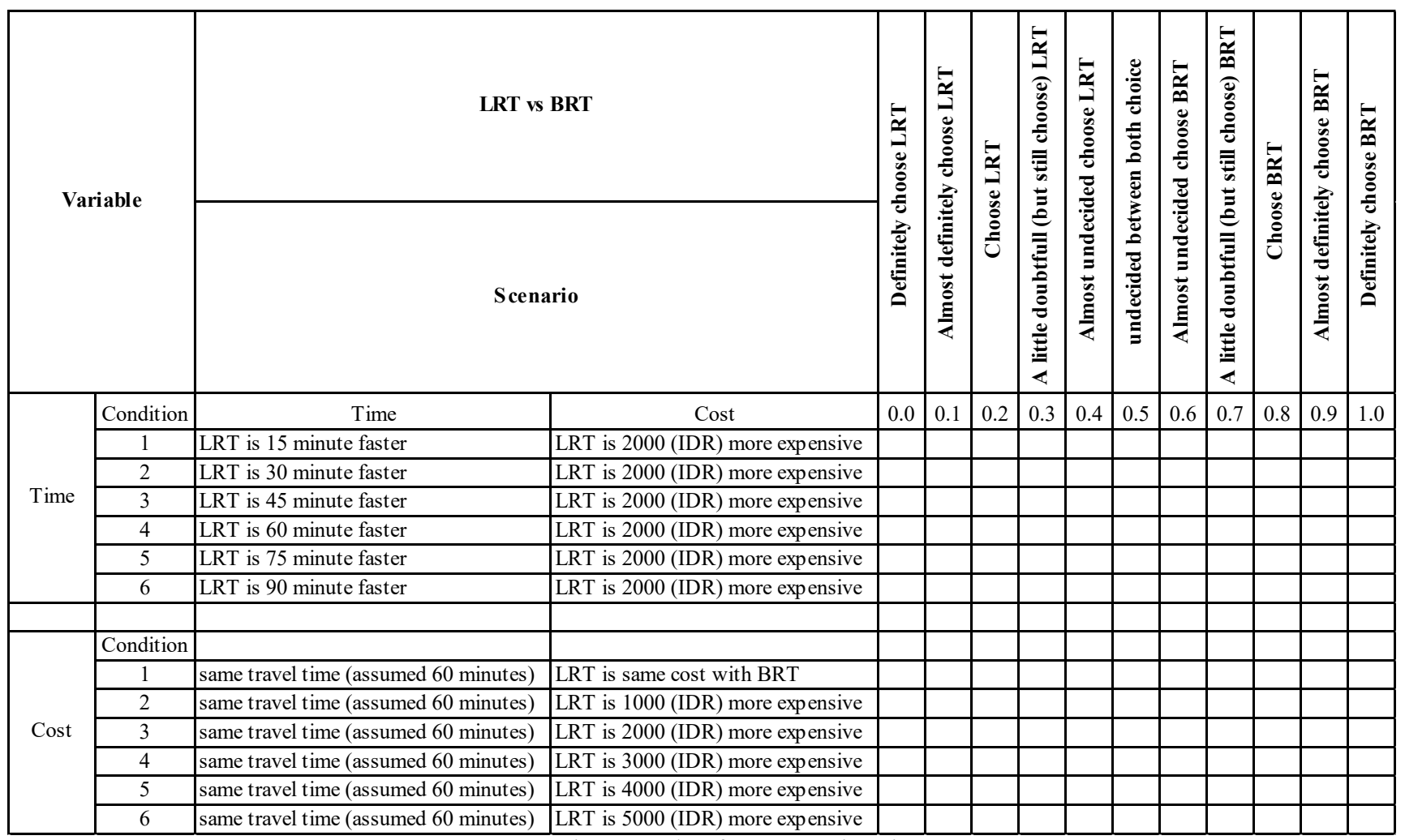

Fig. 1. Stated Preference Questionnaire

To fulfill this figure, respondents should check the most suitable cell that fit their condition. These choices than will be multiplied with the normative value of the choice $(0.00-1.0)$. Then, it is calculated the Average Priority of Respondents (P). Modeling of the mode choice is done using binomial logit regression. The result is used to develop a simple utility function in regression equation, as follows :

$\mathrm{U}_{\mathrm{LRT}}-\mathrm{U}_{\mathrm{BRT}}=\mathrm{a}+\mathrm{bX}$

where:

$$
\begin{gathered}
a=\frac{\sum x^{2} \sum Y-\sum x \sum x Y}{n \sum x^{2}-\left(\sum x\right)^{2}} \\
b=\frac{n \sum x^{2}-\sum x \sum x Y}{n \sum x^{2}-\left(\sum x\right)^{2}}
\end{gathered}
$$

$\mathrm{a}=$ constant of the utility function;

$\mathrm{b}=$ variable coefficient of the utility function;

$\mathrm{X}=$ independent variable;

$\mathrm{Y}=$ dependent variable, and the choice probability

The probability of mode choice based on time difference and cost difference are calculated using logit binomial equation as follows :

$$
P_{L R T}=\frac{\exp U_{L R T}-U_{B R T}}{1+\exp U_{L R T}-U_{B R T}}
$$

Number of respondents is 100 people. The interviews were conducted in a scattered manner, covering $80 \%$ of Semarang City so that the results of the interviews could represent the preferences of the existing public transit users in Semarang City.

\section{Results}

\subsection{Respondent Preference}

After the data for Figure 1 is completed, the Average Priority of Respondents can be calculated as shown in Table 1. This table will be used to calculate the magnitude of the constant (a) and coefficient (b) in the utility function at the following stage:

\begin{tabular}{|c|c|c|c|}
\hline Variable & $\begin{array}{c}\mathbf{X 1} \\
\text { Time Difference } \\
\begin{array}{c}\left(\Delta \mathrm{t}=\mathbf{t}_{\mathrm{LRT}}-\mathbf{t}\right. \\
\text { BRT })\end{array} \\
\end{array}$ & $\begin{array}{c}\mathrm{X} 2 \\
\text { Cost Difference } \\
\left(\begin{array}{c}\Delta \mathrm{c}=\mathbf{c}_{\mathrm{LRT}}- \\
\left.\mathbf{c}_{\mathrm{BRT}}\right)\end{array}\right. \\
\end{array}$ & $\begin{array}{c}\text { Y } \\
\text { Average } \\
\text { Priority }\end{array}$ \\
\hline \multirow{6}{*}{ 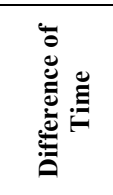 } & 15 & 2000 & 0.452 \\
\hline & 30 & 2000 & 0.372 \\
\hline & 45 & 2000 & 0.293 \\
\hline & 60 & 2000 & 0.243 \\
\hline & 75 & 2000 & 0.213 \\
\hline & 90 & 2000 & 0.173 \\
\hline \multirow{6}{*}{ 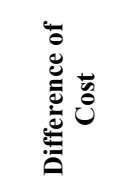 } & 0 & 0 & 0.443 \\
\hline & 0 & 1000 & 0.507 \\
\hline & 0 & 2000 & 0.585 \\
\hline & 0 & 3000 & 0.657 \\
\hline & 0 & 4000 & 0.703 \\
\hline & 0 & 5000 & 0.743 \\
\hline
\end{tabular}

TABLE I

(5) AVERAGE PRIORITY OF RESPONDENTS 


\subsection{Utility Function}

Utility function is developed from Table 1, using equation (3) - (5). The results are as follow :

a. Utility function for difference of time : $\mathrm{U}_{\mathrm{LRT}}-$ $\mathrm{U}_{\mathrm{BRT}}=-0.483+0.0036 \mathrm{X}$

b. Utility function for difference of cost : $\mathrm{U}_{\mathrm{LRT}}-$ $\mathrm{U}_{\mathrm{BRT}}=-0.452+0.000062 \mathrm{X}$

\subsection{Probability of Mode Choice}

Based on time difference, the probability of mode choice are as follow :

$$
\mathrm{P}_{\mathrm{LRT}}=\frac{\exp ((-0,483)+0.0036 x)}{1+\exp ((-0,483)+0.0036 x)}
$$

Using equation (9), the probability selection of modal choice is based on the variable time (x) set from the range of 60 minutes to +60 minutes with gradual changes of 5 minutes. The magnitude of the variable time range set -60 minutes to +60 minutes is based on the assumption that the amount is a logical amount of travel time difference. More specifically, the results of the probability calculation of the LRT mode selection for each variable of travel time can be seen in Fig. 2 and Fig. 3.

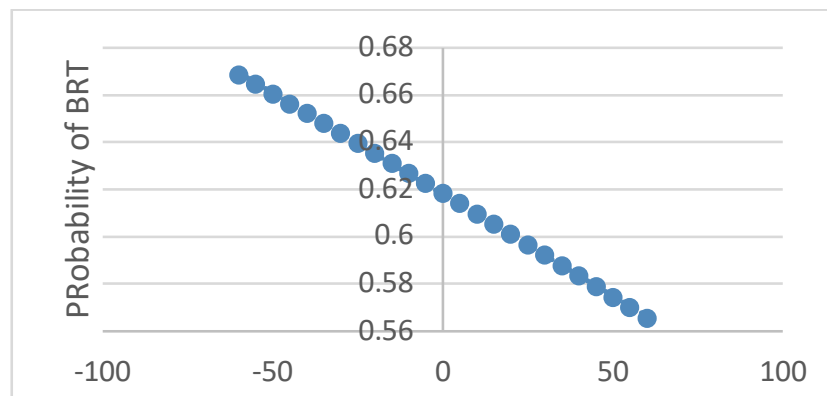

time difference between BRT and LRT $\Delta \mathrm{t}=\mathrm{tBRT}-\mathrm{tLRT}$

Fig. 2. Probability of Mode Choice based on Travel Time (-60 - 60 minutes)

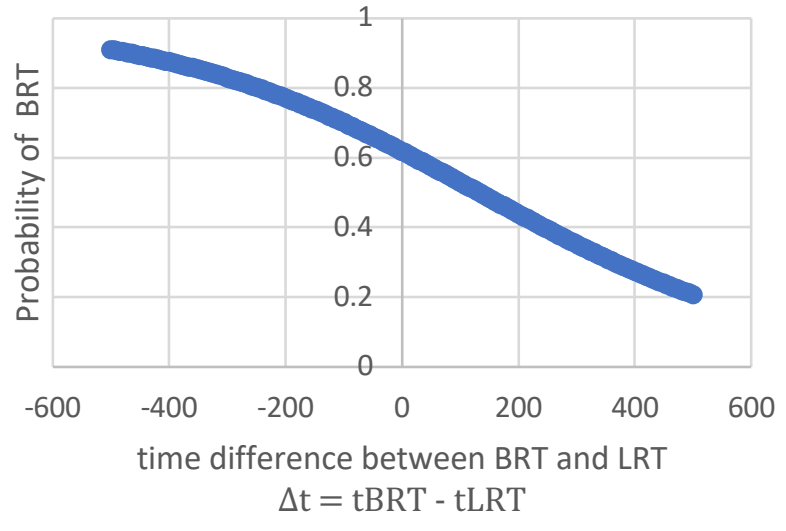

Fig. 3. Probability of Mode Choice based on Travel Time (-500 - 500 minutes)
The first quadrant area (the right side) in Fig. 2 and Fig. 3 illustrates the situation in which LRT has a faster travel time than BRT, while quadrant 2 area (the left side) describes the situation in which LRT is longer than BRT. Figure 2 and Figure 3 are in accordance with the logic that has been built previously so that in the first quadrant, the probability of BRT selection decreases while in the second quadrant the probability of BRT selection increases. But in this discussion, the chart will only be discussed in quadrant one because the conditions in quadrant two are irrelevant. This is because the LRT travel time which has an exclusive lane is confirmed to be faster than the BRT operating on the road in conjunction with private vehicles and other public vehicles.

Fig. 2 explains that if LRT travel time is the same as BRT, then $61.8 \%$ of BRT users will still choose BRT and the rest, while BRT passengers who will move to LRT are only $38.2 \%$. If LRT travel time is 60 minutes faster, the probability of BRT election dropped to $56.5 \%$, the difference in probability reduction was $5.3 \%$. In contrast, the probability of choosing LRT increased to $43.5 \%$, or increased from the same travel time condition of $5.3 \%$. If the LRT travel time 60 minutes longer, the probability of BRT selection increased to $66.8 \%$ difference in increase by $5 \%$. Conversely, the probability of choosing LRT decreased to $33.2 \%$, or decreased from the same travel time condition of $5 \%$.

Changes in the probability of the selection of BRT and LRT that are relatively small indicate that the comparison of LRT and BRT travel times is not sensitive for the people of Semarang City in determining the mode of transportation choices. This is evidenced by the results of the probability calculation, the biggest change in probability magnitude is only $5.3 \%$. If LRT is built and operates in the near future, the impact on the transfer of passengers from BRT to LRT is large. This can be proven from the results of the probability calculation of the selection of LRT by $38.2 \%$ if the LRT condition has the same travel time as the BRT. In its realization, it is ascertained that the probability of LRT selection will be greater than $38.2 \%$, because the LRT which has exclusive movement lines must be faster than the BRT mode which runs simultaneously with private transport and other public transportation.

In Fig. 3, extrapolation of data is used, the difference in travel time from -500 minutes to 500 minutes, but in this discussion only used travel time difference from -60 to 60 minutes. Extrapolation of up to 1000 minutes travel time difference is done to prove that the graph of the binomial logit function difference is a non-linear graph

Based on cost difference, the probability of mode choice are as follow :

$$
P_{\text {LRT }}=\frac{\exp ((-0,452)+(0,000062) x)}{1+\exp ((-0,452)+(0,000062) x)}
$$

Using equation (10), the probability calculation of the mode selection with variable $\mathrm{x}$ is the cost of travel. The cost variable is determined by the range of $\mathrm{Rp} .10,000.00$ to $+\mathrm{Rp}$. $10,000.00$ with gradual changes of Rp. 500.00. The amount of the variable cost is determined in such a way because it is considered the most logical. To be more clear, the results of 
the calculation of the probability of modal selection on each magnitude of the cost variable can be seen in Fig. 4 and Fig. 5.

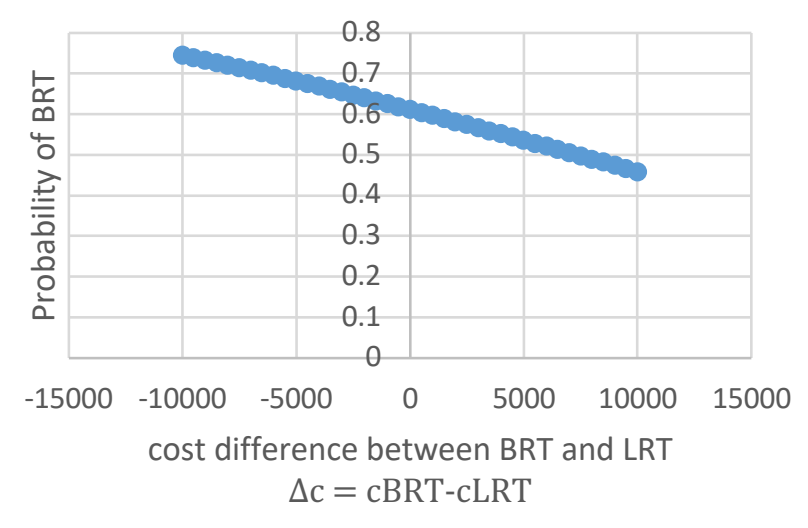

Fig. 4. Probability of Mode Choice based on Cost (-10,000 10,000 rupiahs)

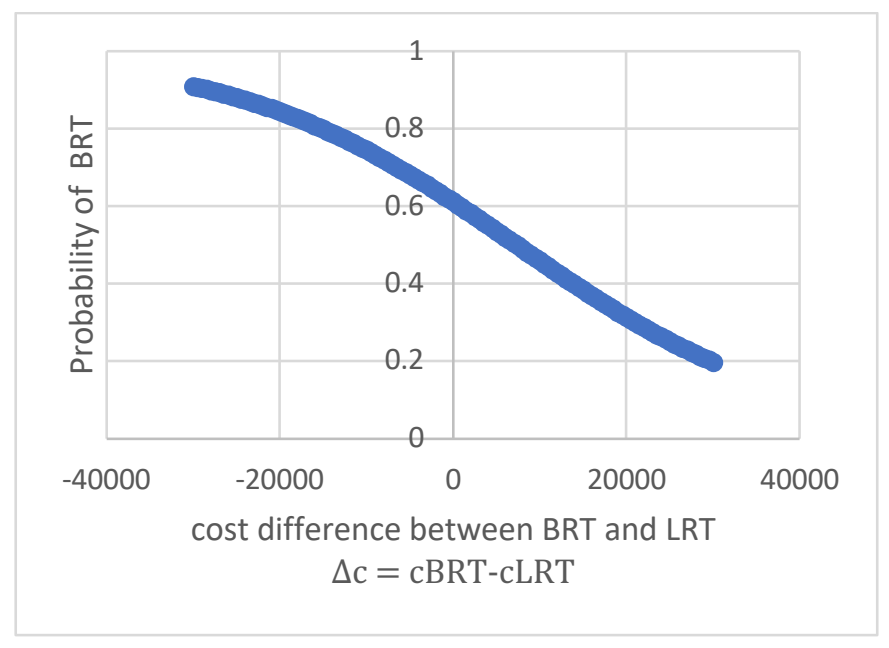

Fig. 5. Probability of Mode Choice based on Cost $(-30,000-$ 30,000 rupiahs)

In Fig. 4 and Fig. 5, the quadrant region of one graph illustrates the situation in which LRT have cheaper travel costs than BRT, while the quadrant two areas describe the conditions in which LRT are more expensive than BRT. Graphs 4 and 5 are in accordance with the logic that has been built before, it is evident that in the first quadrant the probability of BRT selection has decreased while in the second quadrant has increased. But in this discussion, the graph will only be discussed in quadrant two because the conditions in quadrant one is irrelevant. This is because LRT travel costs are certainly more expensive than BRT because LRT operating costs are higher.

In Fig. 4, it is explained that if LRT travel costs the same as BRT, then $61 \%$ of the BRT mode users will still use the BRT mode and the rest, or $39 \%$ will move to BRT. The expensive travel time of Rp.10,000.00, the probability of BRT election increased to $74.4 \%$, the difference in probability increase was $13.4 \%$. Conversely, there is a decrease in the probability of LRT selection, which is to be $25.6 \%$, or a decrease of $13.4 \%$ of the probability when the condition of the cost of travel between LRT and BRT is the same. When conditions for LRT travel costs are Rp.10,000.00 cheaper, the probability of BRT elections decreases to $45.8 \%$ Difference in probability reduction by $15.2 \%$. Conversely, there is an increase in the probability of LRT selection being $54.2 \%$, or an increase of $15.2 \%$ of the probability when the scenario of LRT and BRT travel costs is the same.

Changes in the probability of selecting BRT and LRT based on relatively large travel cost variables indicate that the ratio of LRT and BRT travel costs is sensitive for the people of Semarang City in determining the choice of transportation modes. This is evidenced by the results of calculations that show the greatest probability change of $15.2 \%$. If LRT is built and operates in the near future, the impact on the transfer of passengers from BRT to LRT is large. This can be proven from the results of the probability calculation of LRT selection by $39 \%$ if LRT conditions have the same travel costs as BRT. But in reality, it is certain that the probability of the selection of LRT will be smaller than $39 \%$, because in the LRT tariff fixing must exceed the existing BRT tariff, this will reduce the probability of LRT below $39 \%$.

In Figure 4, extrapolation of LRT travel cost data is used from more expensive Rp. 30,000.00 to Rp. 30,000.00 cheaper, but in this discussion only use extrapolation of cost differences from more expensive Rp.10,000.00 to cheaper Rp.10,000.00. Modification of the difference in travel costs up to Rp. $30,000.00$ is done to prove that the graph of the binomial logit function difference is a non-linear graph.

\section{CONCLUSION}

Based on the analysis of preferences that have been carried out, when viewed from the comparison of travel costs and travel time between LRT and BRT shows that Trans Semarang users prefer to use Trans Semarang compared to LRT based on the following four premises: (1) When the LRT has the same travel time as Trans Semarang, the probability of LRT selection is $38.2 \%$. (2) When the LRT is 60 minutes faster than Trans Semarang, the probability of choosing the LRT increase to 43.5 percent. (3) When the LRT tariff is the same as Trans Semarang, the probability of the LRT election is $39 \%$. (4) When the LRT travel fare is Rp.10,000.00 higher than Trans Semarang, the probability of the LRT election decreases to $25.6 \%$.

\section{ACKNOWLEDGEMENT}

This paper is part of an on-going research supported by Diponegoro University

\section{REFERENCES}

1. Gray, B. H., "Urban Public Transportation Glossary," Transportation Research Board, 2013

2. Kroes, Eric P and Sheldon, Robert J., "Stated Preference Methods," Journal Of Transport Economic and Policy, 1988.

3. Peraturan Mentri Perhubungan Republik Indonesia Nomor PM 17 Tahun 2018 tentang Pegoman Tata Cara Perhitungan dan 
Penetapan Tariff Orang Dengan Kereta Api. Jakarta : Kemenhub, 2018.

4. Tamin, Ofyar, Z, "Perencanaan dan Permodelan Transportasi," Penerbit ITB: Bandung, 2000.

5. O.I. Tirimba, "State Preference Theorem: Describing the Traditional Model," International Journal of Scientific and Research Publications, Volume 4, Issue 6, 1 ISSN 2250-3153, Department of Finance and Economics, Jomo Kenyatta University of Agriculture and Technology, June 2014 .

6. Transportation Research Board, "This Is Light Rail Transit," Washington, D.C., 2000

7. Vuchic, R. Vukan, "Urban Transit Operations, Planning, and Economics," Hoboken, New Jersey. Published by : John Wiley \& Sons,Inc, 2004.

8. Wong, Stanley., "The Foundations of Paul Samuelson's Revealed Preference Theory," New York, NY. Published : Routledge, 2006. 